\title{
Importance of the Slogans as a Brand Communication Tool of Tourist Destinations
}

\author{
$\mathrm{PhD}$ candidate Marianna Aleksandrova \\ University of Economics - Varna, Varna, Bulgaria \\ marianna.aleksandrova@ue-varna.bg
}

\begin{abstract}
Communication tools are an important part of marketing activities for tourism brands positioning. The hereby article aims at examining the impact of slogans, which are part of the destinations 'communication strategies, on the intensity of destinations' visits. The subject of this study is to unveil the characteristics of the slogans of four receptive areas. The applied research methods used for achieving the goal are as follow: literature review, analysis and synthesis of secondary information sources. Statistics on the number of destination visits are used as a quantitative indicator to evaluate the effectiveness of the slogans.
\end{abstract}

Keywords: Slogan, Communication Tools, Tourism Branding, Destinations, International Tourism

JEL Code: Z300, Z330; doi:10.36997/IJUSV-ESS/2019.8.3.154

\section{Въведение}

Туризмът е приоритетна индустрия за насьрчаване на растежа и развитието на глобалните икономики. Необходимостта от установяването на трайни връзки с туристите обуславя обективна необходимост от приложение на брандинг стратегии на туристическите дестинации. Брандингът на туристическа дестинация е система от последователни процеси и стратегии, чиято цел е популяризирането на идентичността на територията пред потенциалните потребители (туристи, туроператори, авиокомпании, инвеститори) посредством комуникационни инструменти и стратегии. Според признатия експерт в областта на бранд мениджмънта професор Давид Акер идентичността на бранда е: „начинът, по който създателите му желаят той да бъде възприеман. Идентичността е серия от уникални ключови асоциации, които целенасочено се свързват с продукта““ (Aker, 2003). Като дефинира бранд идентичността, Жан Ноел Капферер включва емоционалния компонент и стойността на продукта: „Идентичността на бранда изгражда връзка между него и потребителите, указвайки функционални, емоционални преимущества, изгоди, самоизразяване и относителна стойност“ (Kapferer, 2000). Следователно идентичността на бранда (Brand Identity) е от решаващо значение за успешното позициониране и диференциация на носителя. Тя се формира от създателите на бранда и представлява сбор от отличителните елементи на носителя, имплементирани чрез визуални и вербални ефекти (комуникационни елементи), които предизвикват силно емоционално въздействие върху целевите аудитории.

Нарастващата роля на идентичността като средство за диференциация на туристическите територии определя мотива за избор на предмет на изследване в настоящата разработка. Тя представлява опит за конкретизация на ролята и значението на слогана като съставна част и комуникационен елемент за развитието на бранда. Поддържаната теза в разработката е, че сам по себе си слоганът не е в състояние да влияе на туристическата мотивация за посещение на конкретна територия, но успешното интегриране на креативно послание в комуникационната стратегия за позициониране на бранда повишава осведомеността и привлича вниманието на потенциалните посетители. Въпреки, че е малка част от маркетинговата стратегия за създаване и позициониране на туристическия бранд, функцията на слогана е свързана с предаване на информация за бранда, респективно играе важна роля във формирането на асоциации към носителя. Обект на изследване са слоганите на туристически дестинации. Предмет на изследване са комуникационните стратегии, 
обобщени като вербални комуникационни елементи на бранда, под формата на слоган. Последният е ефективен, ако привлича внимание, чрез кратко и запомнящо се мото или фраза, мотивиращи маркетингови, рекламни и др. кампании. Целта на статията е проучване на влиянието на слоганите, като част от комуникационните стратегии на дестинациите, върху интензивността на посещенията в тях. Броят на посетителите в туристическите дестинации е един от традиционните показатели за ефективност на приложените национални и регионални маркетингови стратегии, за които слоганът е от решаващо значение. Използваните методи са литературен обзор, теоретичен анализ и синтез на вторични информационни източници.

\section{1. Сыщност и дефиниране на слогана като комуникационен елемент на бранд идентичността}

Според класическата теория брандът е: „име, символ или тяхна комбинация, които са предназначени за идентифициране на дадени стоки (услуги), от тези на конкурентите“ (Kotler, 2005). В тази връзка от решаващо значение за пазарното позициониране на брандовете са комуникационните инструменти, защото са средство за визуализиране на идентичността им. В сферата на продуктовите брандове те са: бранд име (Brand Name), текстови послания; специфичен термин (Brand Slogane), дизайнерски визуални елементи (Brand Logotype). Същите са приложими при брандирането на туристически дестинации.

Бранд името е един от елементите, които помагат на потребителите да идентифицират и разграничават различни потребителски брандове. То трябва да бъде внимателно подбрано, защото е свързано с темата и категорията на продукта. За разлика от сферата на потребителските брандове името на туристическата дестинация вече съществува, обикновено е изпълнено с исторически смисъл и съответства на географското наименование на територията. Основна задача е да му бъде предадено специфично значение чрез слоган (лозунг, съобщение, бранд термин, послание) и визуална разпознаваемост посредством логотип.

Логотипът може да бъде определен като визуална идентичност на дестинациите. Функциите му са свързани с идентификация, диференциация и припомняне. Ефективното лого разграничава носителя на бранда от останалите и спомага за изграждане на асоциации. В допълнение дизайнът на логото понякога може да предаде аспекти от същността на дестинациите (забавление, топлина или енергия).

Недостатьк на логотипа е, че посланията, които предава, са ограничени. Затова слоганът е от ключово значение за успешната връзка между вербалната (име) и визуална идентичност (лого). Въпреки ключовата им важност за позициониране на бранда слоганите на туристически дестинации не са обект на задълбочени научни изследвания. Наличните изследвания са фокусирани върху съдържанието на посланията. Липсата на задълбоченост навярно обяснява и причината за отсъствие на критерии и стандарти при изследването на слоганите на туристически дестинации. Сред литературните източници в сферата на продуктовото брандиране се отличават следните определения за понятието „слоган“ (Табл. $1)$.

От посочените в Табл. 1 дефиниции става ясно, че слоганът трябва да бъде максимално кратьк и разбираем, но същевременно да разказва история, пробуждайки асоциации, свързани с ползите, които потребителите ще получат, ако се доверят на носителя. Като акцентират върху важността му, някои експерти в областта го определят като „мост“ между бранд името и бранд логотипа (Kohli, 2007). В контекста на брандинга на туристическите дестинации слоганът съобщава ключовите им характеристики по красноречив начин. Наличието на ясно формулирана основна концепция, изразена чрез послание, а не множество еквиваленти (често дори противоречиви), значително опростява процеса на въздействие върху съзнанието на потенциалните посетители. 
Таблица 1. Дефиниране на термина „слоган“

\begin{tabular}{|c|l|}
\hline Автор/и & \multicolumn{1}{|c|}{ Дефиниция } \\
\hline Доганов, Дуранкев, & $\begin{array}{l}\text { „Слоганът е основна рекламна константа, представляваща } \\
\text { кратък ясен и лек за произнасяне израз, сьдържащ като } \\
\text { главен логически елемент стоката, тьрговската марка, } \\
\text { услугата или мястото за продажба.“; }\end{array}$ \\
\hline $\begin{array}{c}\text { Supphellen \& } \\
\text { Nygaardsvick, (2002) }\end{array}$ & $\begin{array}{l}\text { „Слоганите се запаметяват по-лесно, ако сьдържат рима } \\
\text { или алитерация.“; }\end{array}$ \\
\hline Keller, (2003) & $\begin{array}{l}\text { „Това е кратка фраза, използвана за предаване на } \\
\text { описателна и убедителна информация за бранда.“; }\end{array}$ \\
\hline Pike, (2004) & $\begin{array}{l}\text { „Кратките слогани са лесни за запомняне от целевите } \\
\text { аудитории.“; }\end{array}$ \\
\hline Kohli, (2007) & $\begin{array}{l}\text { „За да е ефективен и успешен, слоганът трябва да е кратьк, } \\
\text { интересен, заслужаващ доверие, уникален, прям и } \\
\text { съответстващ.“; }\end{array}$ \\
\hline Letho, (2014) & $\begin{array}{l}\text { „Слоганите трябва да са формирани от достъпни думи, } \\
\text { които предизвикват положителни асоциции.“; }\end{array}$ \\
\hline Donaire \& Galí, (2016) & $\begin{array}{l}\text { „Интеграцията на бранда в съдържанието на слогана } \\
\text { способства за формирането на асоциации към носителя“. }\end{array}$ \\
\hline
\end{tabular}

Източник: Таблицата е съставена от автора

Посланията на бранда на дестинациите се създават трудно, защото трябва да се вземат под внимание различни фактори, които са свързани с туристическия опит, социалните, културните, икономическите и политическите условия на територията, обект на брандиране, както и националните особености на целевите аудитории. Ролята на слоганите се отнася до формиране на дългосрочен или средносрочен образ, свързващ съдържанието му с носителя на бранда. Слоганът служи като комуникационен инструмент при позициониране на дестинации. Някои регионални туристически организации са успели да създадат динамични, емоционални и лесно разпознаваеми слогани, които са стратегически са позиционирани на международния туристически пазар. Сред тях е култовият „Аз обичам Ню Йорк“ (I Love New York), който е от края на 70-те години на 20-ти век и се явява най-известният туристически лозунг в историята, трайно позициониран в съзнанието на международната аудитория (Galí, 2017).

\section{2. Анализ на слогани на туристически дестинации}

Един от най-успешните примери за креативен туристически слоган е изключително разпознаваемото послание на Лас Вегас „Каквото се случва в Лас Вегас остава в Лас Вегас“ (What happens in Las Vegas stays in Las Vegas). Дебютьт на регионалния на слоган е през 2003г., а съдържанието създава асоциации за свобода и забавление, приканвайки потенциалните посетители да проявят спонтанност и да се забавляват. Идеята на създателите е свързана с предаването на внушение, че пристигнеш ли в Лас Вегас, можеш да направиш всичко, да бъдеш който искаш и да правиш каквото желаеш, при това градът ще запази тайните ти. Маркетинговата кампания започва като начин за разнообразяване на имиджа на бранда на Лас Вегас чрез поставяне на акцент върху развлекателната индустрия. В резултат се наблюдава $4 \%$ ръст на посещения през следващите години (Фиг.1). Брандът запазва пазарни позиции по време на финансовата криза в периода $2008-2009$ г. и се характеризира с устойчивост през следващото десетилетие. Според международни експерти кампанията и съответният слоган са едни от най-успешните примери в туристическата индустрия. 


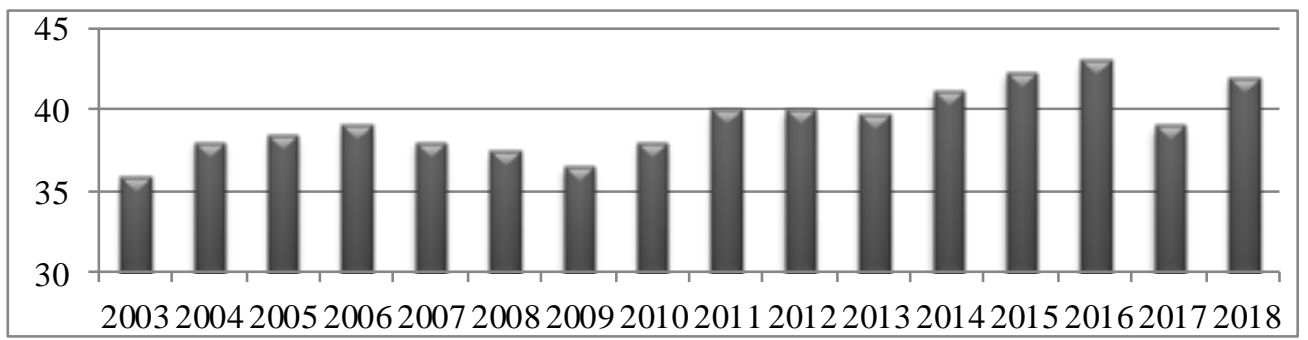

Фигура 1: Брой посетители в Лас Вегас (2003 - 2018г./млн.)

Източник: СЕIC; Международен туризъм:Брой пристигания в Лас Вегас (САЩ)

Действително отличителните слогани увеличават интереса към дестинациите. Доказателство за този феномен е решението на колумбийските власи да насьрчат чуждестранните посещения, за да подобрят икономическото състояние на страната.В тази връзка през 2008г. „Националната експортна комисия“ съвместно с Министерство на търговията, промишлеността и туризма стартират кампания с посланието - „Колумбияединственият риск е да искате да останете!“(Colombia, the only risk is wanting to stay!) Идеята е да бъде неутрализирана дългогодишната репутация на Колумбия като най-опасната държава в Южна Америка. Факт, снижаващ привлекателността на страната сред потенциалните посетители. Създателите стратегически използват асоциациите, утвърдени в съзнанието на милиони хора, свързани с риск, и им придават съвсем ново значение, трансформирайки риска в обещание за положителни емоции. Целта на кампанията е да позиционира Колумбия на международния пазар като алтернатива за ваканционен туризъм, внушавайки, че единственият риск е да се влюбите в нейните пейзажи, хора, храна, панаири, фестивали, занаяти, цветове и всички преживявания. Като адаптират кампанията на 9 езика, държавните власти си поставят амбициозна цел за достигане до европейска аудитория. Въпреки че към настоящия момент идеята за конкурентоспособност на Колумбия на европейски пазар е по-скоро утопична, входящият туризъм в страната след старта на кампанията се характеризира с постоянен растеж. По данни на Колумбийския статистически институт след стартиране на кампанията посещенията в страната са се увеличили с почти $150 \%$ за 10 години. Най-голям дял на посещения реализират туристи от САЩ $(20,8 \%)$, Венецуела (12,8\%) и Аржентина $(6,4 \%) .79$ \% от всички посетители избират дестинацията, мотивирани от условията за ваканционен туризъм.

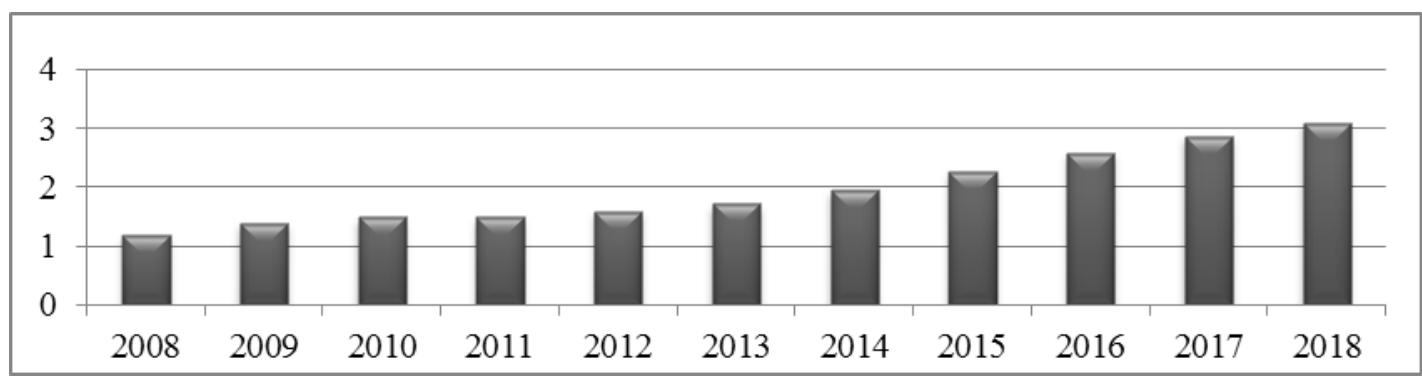

Фигура 2: Брой чуждестранни туристи в Колумбия (2008 - 2018г./млн.)

Източник: Министерство на търговията, промишлеността и туризма - Колумбия

Успешен пример за дестинация, постигнала трайно диференциране и популярност е Испания. Преди повече от 35 години страната стартира маркетингова кампания под надслов „Всичко под сльнцето“(Everything under the sun), което ѝ осигурява диференциация и трайно установяване в съзнанието на целевите аудитории. Въпреки че посланието е базирано на рационални териториални характеристики, Испания успешно се позиционира като водеща 
дестинация за ваканционен туризъм сред европейците. През 1991 г. държавните власти решават, че трябва да покажат дестинацията по нов начин, който да бъде по-активен и „оживен“, съобразен с добре възприемания от туристите страстен характер на населението. В резултат Испания е показана като „отражение“ на посетителското търсене, свързано с нуждата от преживявания и емоции, посредством посланието „Страст към живота“ (Passion for life). Като проявяват постоянство, националните маркетинг организации персонализират бранда, използвайки световноизвестни знаменитости, които показват уникалните характеристики на страната със стил и естетика. Благодарение на ясно формулираната бранд идентичност Испания укрепва своята лидерска пазарна позиция. През 1998 г.,пилотира нова комуникационна кампания с ярък, гъвкав и запомнящ се слоган, който лесно и еднакво се произнася на всички езици-,Браво Испания!“(Bravo Spain!). Като поддържа постоянно висока бранд осведоменост, Испания създава устойчив имидж на модерна страна с качествен и разнообразен туристически продукт.

В опит да усилят индивидуалността на бранда през 2004г., маркетинговите организации стартират нова кампания:,Усмихнете се! Вие сте в Испания!“(Smile! You are in Spain!). Идеята е да бъде надграден емоционалният компонент чрез послание, описващо найточно емоционалното състояние на посетителите по време на пребиваване. Новият слоган поставя специален акцент върху начина и стила на живот в страната, интегрирайки стойността на испанската култура към идентичността на бранда. През следващите 4 години Испания запазва лидерската си позиция сред европейските ваканционни дестинации, като се наблюдава ръст на посещенията от 5,5\% за 3 години.

Резултатите от проведените изследване и мониторинг на националния туристически бранд през 2009г. показват, че Испания е безспорен лидер сред ваканционните дестинации в Европа. В хода на изследването става ясно, че туристическият бранд е слабо разпознаваем сред развиващите се пазари, по-конкретно Азия. Това налага репозициониране на бранда. Националните маркетингови организации си поставят цели свързани с: изграждане на нова идентичност на пазар Европа чрез диференциация на туристическия продукт; позициониране и постигане на висока бранд осведоменост на нови пазари с голям потенциал. В тази връзка през 2010г. стартира кампанията „Нуждая се от Испания“ (I Need Spain), която е предназначена за обновяване на бранд имиджа. Принос за реализацията ѝ имат престижни международни фотографи, режисьори, кулинари, спортисти и др. Това се оказва найуспешната национална кампания на Испания, която се позиционира трайно на международния пазар. Според данните от Фиг.5 посещаемостта на страната се е увеличила с над 50\% в периода $2010-2018$ г.

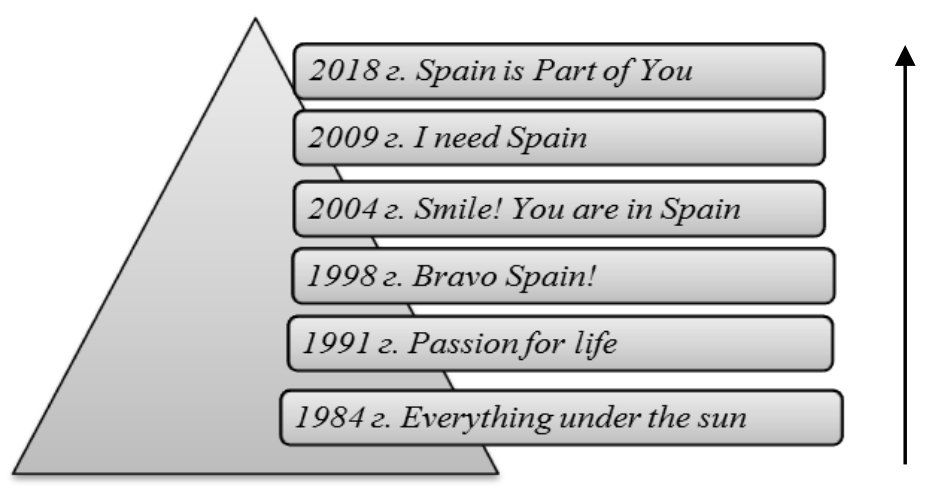

Фигура 3: Еволюция на националния туристически слоган на Испания „от рационалност към чувства“

Испания демонстрира постоянство в надграждането на взаимоотношенията с 
туристите. През 2018г. TurEspaña ${ }^{1}$ инициира нова кампания „Испания в 10 секунди“, която можем да наречем „капания на иновациите“. Тя цели да „накара“ потенциалните туристи да се „влюбят“ и „пожелаят“страната чрез видеоклипове, публикувани в социалните медии от реални посетители. В основата на комуникационната стратегия, провокираща потребителските споделяния, стоят 12 инфлуенсьри ${ }^{2}$ (световноизвестни лидери на мнение от областта на спорта, културата, гастрономията, изкуствата и развлекателната индустрия). Те разказват в социалните медии за уникалността на Испания като туристическа дестинация и предизвикват останалите потребители да направят същото. Като начин за класифициране и организация на дигиталния контент, маркетинг организациите въвеждат хаш таг „Испания в 10 секунди“ (\#SpainIn10Sec), а новият слоган на страната е „Испания е част от теб“ (Spain is Part of You).

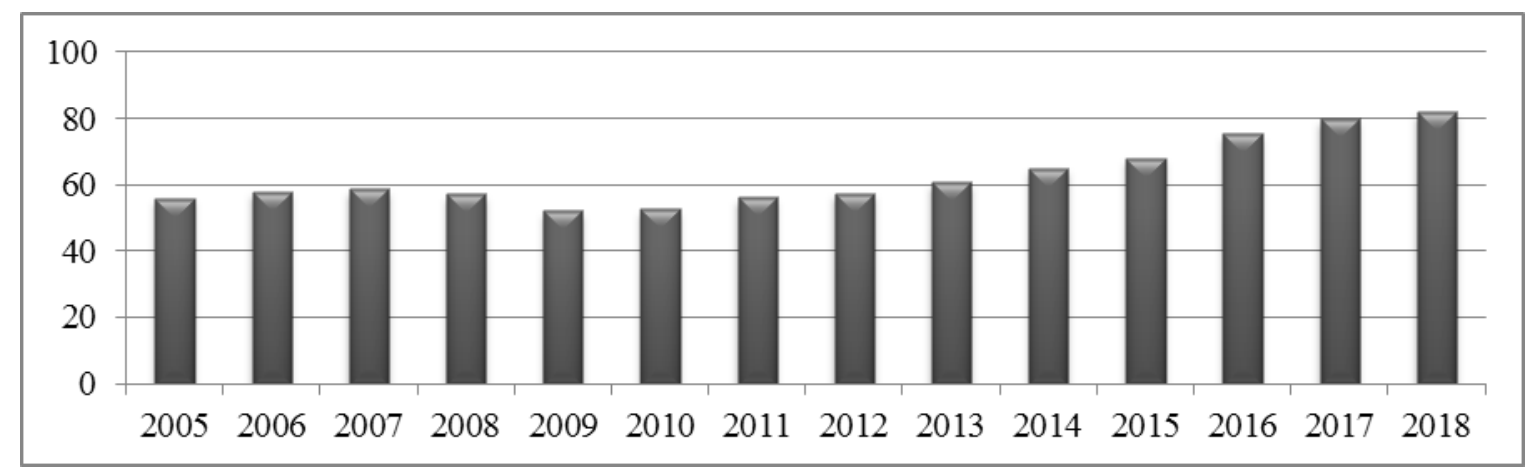

Фигура 5: Брой посетители на Испания (2005 - 2018г./млн.)

Източници: CEIC/ TurEspaña3; Международен туризъм: Брой пристигания в Испания;

През 2013 г. е приложена стратегия за репозициониране на националния туристически бранд на България. Кампанията е представена от слогана „Открий и сподели“(A Discovery to Share). Идеята на създателите (носителите на туристическата политика на Република България) е, да повишат осведомеността на потенциалните посетители, относно разнообразните форми на туризъм, провокирайки целевите аудитории да открият България по нов начин, извън контекста на летния ваканционен туризъм. Слоганът внушава чувство за предполагащо позитивно изживяване, което заслужава да бъде споделено. Целевите аудитории, са традиционните за България емитивни пазари - европейски държави и Русия. Целта на кампанията е разнообразяване на имиджа на страната, като дестинация подходяща за алтернативни видове туризъм. Посланието се характеризира с динамика и провокация, но не може да се определи като уникално, защото може да е релевантно за други рецептивни области. Кампанията се отразява на интензивността на чуждестранни посещения след първата година. Според данните от Фиг. 6 през 2015 г. се наблюдава спад от 3\% . През 2016г. и 2017г. входящия туризъм в страната се характеризира с ръст достигащ $15 \%$. Над 55\% от общия брой посещения в посочения период са реализирани през летния сезон (юнисептември), което можем да приемем като показател, че водещият мотив за посещение е летен ваканционен туризъм. Тенденцията за увеличение се запазва и през 2018г., страната е посетена с 4,4\% повече туристи като превес от 62,4\% отново получава масовия ваканционен туризъм. Статистическите данни дават основание за констатация, че националните брандинг стратегии, приложени през 2013 г. се характеризират с непостоянство, защото водещ мотив за посещение на дестинация България остава ваканционния туризъм.

\footnotetext{
${ }^{1}$ Министерство на индустрията, тьрговията и туризма-Испания;

2 Човек или група от хора, притежаващи авторитет, имащ/и способността да влияят на поведението и/или мнението на обществото, включително върху решенията за реализиране на покупка;

${ }^{3}$ Дьржавен секретариат по туризма на Кралство Испания;
} 


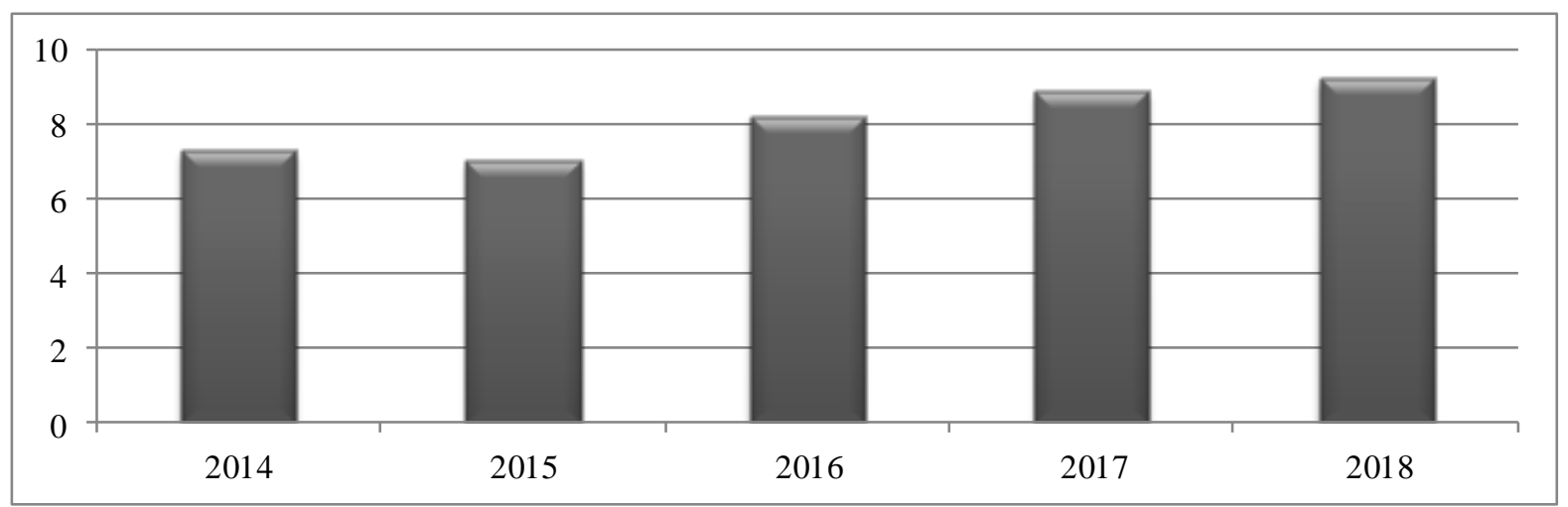

Фигура 6: Брой чуждестранни посетители на България (2014-2018 г./млн.) Източник: Министерство на туризма на Република България

\section{3. Изводи и препоръки}

Създаването на ефективни туристически слогани, които постигат прогнозираните в маркетинговия план резултати, можем да приемем като индикатор за оползотворяване на потенциала на туристическата индустрия в териториите. В хода на анализа бе установено, че основните предизвикателства, свързани със създаването на слоган като комуникационен елемент на бранда на туристически дестинации, произхождат от следните обстоятелства:

Първо, формирането на съобщения, които да разграничават дестинации, притежаващи сходни характеристики, е сложна задача, изискваща постоянство и креативност. Ако посланията са базирани предимно на природни блага (рационална основа), шансът за успешна диференциация се усложнява многократно. Въпреки, че наличието на река, море или планина са отличаващи елементи, не може да наречем посланията с тази ориентация уникални, тъй като лесно биха се адаптирали към други територии със сходни природни ресурси. Освен това фокусирането върху рационални характеристики намалява гъвкавостта на бранда и неговата способност да се адаптира към промените в изискванията на туристите, представители на различни целеви сегменти. Съдържанието на слогана има решаващо значение за позиционирането на бранда. За маркетолозите той е отправна точка за избор на комуникационна стратегия и ориентацията на бранд съобщенията т.е., дали са насочени към търсенето или предлагането. Ако насочеността е към крайния потребител, тогава и емоционалният компонент трябва да бъде интегриран в контента на посланието. В случай че ориентацията е към дистрибутори (туроператори, турагенти, хотелиерски брандове, авиокомпании), е допустимо да изразява рационални териториални характеристики (атрибути на дестинацията);

Bторо, дестинациите притежават множество елементи (природа, култура, традиции, фолклор) и често отправят объркващи послания към аудиториите си, опитвайки се да ги комбинират. Типични примери за това са фразите: „Всичко е тук“, „Целогодишен“„,Открий и сподели“" и др. От литературния преглед става ясно, че успешните послания са комбинация от малко думи, притежаващи ясна същност, отразяващи самоимиджа на дестинацията;

Tрето, слоганите служат като комуникационен инструмент на бранда на множество разнородни и динамични пазари. Едно от най-големите предизвикателства при създаването им е да бъдат адаптивни към особеностите на различни потребителски аудитории, отчитайки техните културни, социални и религиозни различия.Констатациите разкриват, че слоганите трябва с подчертано емоционален компонент;

Четвърто, създаването на национални и регионални туристически слогани изисква задълбочени изследвания на потребностите на целевите аудитории, инвестиции и усилия от страна на националните туристически организации. 
Литературният анализ в комбинация с проучване на международния опит в сферата, дава основание за идентифициране на критерии, на които трябва да отговаря ефективният слоган на туристическа дестинация:

$\checkmark$ Според съдържанието, слоганът трябва да се характеризира с креативност, краткост, релевантност, яснота, уникалност и ритмичност, напомнящ структурата на метономията. При проектиране на съдържанието е желателна интеграция на името на носителя. Например Испания използва тази стратегия при 4 от най-успешните си кампании, аналогични примери са слоганите на Лас Вегас и Ню Йорк;

$\checkmark$ От концептуална гледна точка слоганът трябва да отразява изградената от създателите на бранда идентичност на туристическите места, предизвиквайки асоциации. Той може да бъде: ращиионален (основан на природни характеристики), емоционален (включващ спецификата на емоциите, които посещението в дестинацията пробужда), лидерски (базиран на утвърдени в съзнанието на целевите аудитории преимущества, които дестинацията притежава), сегментационен (фокусиран върху нуждите на точно определен пазарен сегмент). Ефективният слоган трябва да отговаря на контекста на цялостната маркетинг стратегия на туристическите територии;

$\checkmark$ Слоганът трябва да разказва история, която да бъде визуализирана посредством логотипа на дестинацията, т.е. двата комуникационни елемента трябва да хармонират;

$\checkmark$ Слоганът трябва да разкрива определени ползи, които туристьт ще получи по време на пребиваване;

$\checkmark$ Да притежава адаптивност за превод на различни езици;

$\checkmark$ Посланията, които дестинациите отправят трябва да бъдат инспирирани от техните отличителни характеристики (индивидуалност), които да бъдат отражение на потребителското търсене. Слоганът се създава след щателно изследване на потребителските аудитории, за които е предназначен. Той трябва да отразява решение на даден проблем, свързан с потребностите и мотивацията за предприемане на пътуване на потенциалните посетители;

$\checkmark$ Туристическите лозунги трябва да са модифицирани към целевия пазар на туристическа дестинация, т.е. при създаването му трябва да се вземат под внимание отличителните характеристики на територията, носител на посланието, и социо-културните особености на аудиторията, явяваща се получател.

\section{Заключение}

Идентичността е характеристика, която се предава на бранда от създателите му, а имиджът се формира като резултат от обработената в човешкото съзнание информация, относно специфичните му характеристики, предадени чрез бранд комуникационни инструменти и масовизирани посредством комуникационни стратегии. Затова съдържанието на комуникационните елементи на бранда е от особено значение за успешното позициониране и диференциация на туристическите места. Слоганите на туристически дестинации са сложни за създаване в сравнение с продуктовите, защото трябва да вземат под внимание различни фактори, характерни за многокомпонентността на рецептивните области, особеностите на целевите аудитории и спецификите на туристическия продукт.Креативните слоган и логотип придават специфично значение на туристическите места, но трайна диференциация в създанието на потенциални посетители може да бъде постигната чрез надграждане на посланията и своевременната им адаптация към нуждите и динамиката на туристическите пазари.

\section{References}

1. Aker, D. (2003) Sozdanie silynayh brendov. Moskva: "Grebennikova"

2. Doganov, D., Durankev, B. (2001) Balgarska reklamna entsiklopediya. Sofiya: Siela

3. Kapferer, J.,N.(2000) Strategic brand management: new approaches to creating and evaluating 
brand equity. London,: Kogan Page Ltd.

4. Keller, K. (2003) Strategic brand management: Building, measuring and managing brand equity. Upper Saddle River, New Jersey: Prentice-Hall

5. Kotler, Ph., Gertner, D., (2005). How Can a Place Correct a Negative Image?. Place Branding. 1(1): $50-57$

6. Letho, X., Lee, G., \& Ismail, J. (2014) Measuring congruence of affective images of destinations and their slogans. International Journal of Tourism Research, 16(3), 250-260

7. Galí, N., Camprubí, R., Donaire, J. (2017) Analysing tourism slogans in top tourism destinations. Journal of Destination Marketing \& Management

8. Pike, S. (2004) Destination brand positioning slogan: Towards the development of a set of accountability criteria. Jornal Acta Turística, 16(2):, pp.102-124

9. Supphellen, M., \& Nygaardsvik, I. (2002) Testing country brand slogans: Conceptual development and empirical ilustration of a simple normative model. Jornal Brand Management, 384-395.

10. UNWTO, European Travel Commission and Anholt, S. (2009) Handbook on Tourism Destination Branding. Published by the World Tourism Organization and the European Travel Commission

11. Ministry of Tourism of the Republic of Bulgaria (2019) Available at: http://www.tourism.government.bg/bg/kategorii/statisticheski-danni/ (Accessed: 17 July 2019)

12. National Statistical Institute of Bulgaria Available at: http://www.nsi.bg/ (Accessed: 19 July 2019)

13. Ministry of Commerce, Industry and Tourism (Colombia) Available at: http://www.mincit.gov.co/ (Accessed: 19 July 2019)

14. Ministry of industry, trade and tourism https://www.tourspain.es/ (Accessed: 17 July 2019)

15. Spain ES: International Tourism: Number of Arrivals Available at: https://www.ceicdata.com/en/spain/tourism-statistics (Accessed: 28 July 2019)

16. Colombia's CO: International Tourism: Number of Arrivals Available at: /https://www.ceicdata.com/en/colombia/tourism-statistics (Accessed: 28 July 2019)

17. Number of visitors to Las Vegas in the United States from 2000 to 2018 Available at: https://www.statista.com/statistics/221042/visitors-to-las-vegas/ (Accessed: 28 July 2019)

18. Spanish Tourist Board Slogans List Available at https://www.spain.info/ (Accessed: 29 July 2019)

19. Spain is part of you campaign Available at : http://spainin10sec.com/(Accessed: 29 July 2019) 